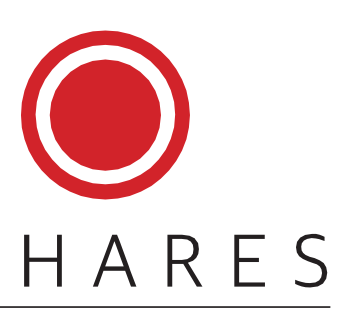

REVISTA DO DEPARTAMENTO DE EDUCAÇ̈O - UNIFESP

\title{
ESTUDANTES JOVENS E ADULTOS COM DEFICIÊNCIA E A PRÁTICA DOCENTE NA PERSPECTIVA FREIRIANA
}

\author{
ESTUDIANTES JÓVENES Y ADULTOS COM DISCAPACIDAD Y PRÁTICA \\ DOCENTE DESDE LA PERSPECTIVA FREIRIANA
}

\author{
YOUNG AND ADULT STUDENTS WITH DISABILITIES AND TEACHING \\ PRACTICE FROM THE FREIRIAN PERSPECTIVE
}

\author{
Marcela Fontão Nogueira \\ Universidade Federal de São Carlos \\ Marcela.fontao@gmail.com \\ Juliane Aparecida de Paula Perez Campos \\ Universidade Federal de São Carlos \\ jappcampos@gmail.com
}

\begin{abstract}
Resumo O presente estudo traz como principal questionamento a maneira como professores da sala de aula regular constroem sua prática docente junto aos estudantes jovens e adultos com deficiência. Tem por objetivo analisar as narrativas dos professores sobre sua prática pedagógica, percepções e reflexões sobre a atuação junto a esses estudantes. Trata-se de um estudo de caso realizado em um Centro Integrado de Educação de Jovens e Adultos (CIEJA) no município de São Paulo. Esse estudo contou com a participação de quatorze professores do ensino fundamental I e II. O instrumento utilizado para coleta de dados foi um questionário, e a análise dos dados foi estruturada a partir de ciclos de codificação. Os resultados apresentados indicaram que os professores: flexibilizaram o currículo por meio da reflexão sobre a sua própria prática; foram dialógicos no planejamento e na prática, valorizando os saberes dos educandos; e, finalmente, o fizeram de maneira colaborativa, construindo sua prática docente em parceria com outros professores e com os próprios estudantes.
\end{abstract}

Palavras-chave: Educação de jovens e adultos. Educação das pessoas com deficiência. Prática docente.

Resumen: El presente estudio plantea como la cuestión principal, la forma como los educadores en las clases construyen su práctica junto a los estudiantes jóvenes y adultos con discapacidad. Su objetivo es analizar las narrativas de los docentes sobre su práctica pedagógica, percepciones y reflexiones sobre su desempeño frente a estos estudiantes. Este es un caso de estudio realizado en un Centro Integrado de Educación de Jóvenes y Adultos (CIEJA) en la ciudad de São Paulo y contó con la participación de catorce maestros de la escuela primaria I y II. El instrumento utilizado para la recogida de datos fue un cuestionario y el análisis de los datos se estructuró a partir de ciclos de codificación. Los resultados presentados indicaron que los docentes flexibilizaron el currículo al reflexionar sobre su propia práctica; fueron dialógicos en la planificación y en la práctica, valorando los conocimientos de los estudiantes, y finalmente, lo hicieron de forma colaborativa, construyendo su práctica docente en sociedad con otros profesores y con los propios alumnos. 
Palabras clave: Educación de personas jóvenes y adultas. Educación de personas con discapacidad. Práctica docente.

\begin{abstract}
This study brings as its main question the way teachers in the regular classroom build their teaching practice with young students and adults with disabilities. Its purpose is to analyze the teachers' narratives about their pedagogical practice, perceptions, and reflections on their performance before these students. This is a case study carried out in an Integrated Center for Youth and Adult Education (CIEJA) in the city of São Paulo, with the participation of fourteen elementary school teachers I and II. The instrument used for data collection was a questionnaire and the data analysis was structured from coding cycles. The results presented indicated that teachers made the curriculum more flexible by reflecting on their own practice; they were dialogical in planning and in practice, valuing the students' knowledge; and, finally, they did so collaboratively, building their teaching practice in partnership with other teachers and with the students themselves.
\end{abstract}

Keywords: Youth and Adult Education. Education of People with Disabilities. Teaching Practice.

\title{
Introdução
}

O processo histórico da Educação de Jovens e Adultos (EJA) no contexto brasileiro tem como marco principal a década de 1960, com o surgimento dos estudos do educador Paulo Freire (1921-1997). Pensando cronologicamente no que o antecedeu e sucedeu, autores como Haddad e Di Pierro (2000), Beisiegel (2003), Galvão e Di Pierro (2013) discutem a história da EJA. Tal discussão abrange desde o período caracterizado pela ausência de políticas públicas (de 1579 a meados de 1930), o surgimento das primeiras políticas públicas (Constituição Federal de 1934), a ditadura no Brasil (que impulsionou o surgimento do Mobral e a institucionalização do ensino supletivo), até a conquista dos direitos educativos vindos com a promulgação da Constituição de 1988 (artigo 208') e da Lei de Diretrizes e Bases da Educação (LDB) 9496/96 (artigos $37^{\circ}$ e 38).

Com base nesses autores, é possível afirmar que, desde sempre, o caráter reparador foi a principal característica da EJA, já que o público dessa modalidade de ensino é constituído, justamente, por jovens e adultos que, pelos mais diversos motivos, foram privados de concluir a educação básica na suposta idade certa. A ideia de resistência e transformação social foi teorizada na ampla obra de Freire, referencial teórico adotado neste estudo. Arroyo (2017, p. 26) traça um importante paralelo entre a escolarização tardia e o direito a uma vida justa e humana. Para ele:

Este é o lugar da EJA nas hierarquias escolares: a última porta de emergência no hierárquico percurso escolar a transportar esperanças do último ônibus. Da última viagem? Nunca foi fácil, nessa última viagem, reverter as hierarquias escolares, muito menos as hierarquias sociais, raciais, sexuais de que os adolescentes, jovens e adultos são vítimas históricas. 
Assim, ainda que os dispositivos legais supracitados, ou que documentos internacionais como a Declaração Mundial sobre Educação para Todos, aprovada em Jomtien (1990), e a Declaração de Hamburgo sobre a Educação de Adultos (1997) discutam e garantam o direito e o acesso à educação para jovens e adultos, milhares de cidadãos brasileiros permanecem fora do sistema educacional. Segundo dados da Pesquisa Nacional por Amostra de Domicílio (PNAD) de 2018, divulgada em junho de 2019 pelo Instituto Brasileiro de Geografia e Estatística (IBGE), o Brasil possui 11,3 milhões de pessoas em situação de analfabetismo (6,8\% da população) e $34 \%$ da população não tem o ensino fundamental completo.

O município de São Paulo possibilita o acesso à educação àqueles que não concluíram a escolarização no momento adequado, por meio de cinco modalidades de Educação de Jovens e Adultos: a EJA regular, o Movimento de Alfabetização (MOVA), o Centro Integrado de Educação de Jovens e Adultos (CIEJA), o Centro Municipal de Capacitação e Treinamento (CMCT) e a EJA modular.

O CIEJA é um projeto educacional regulamentado pela Lei Municipal 15.648 de 14 de novembro de 2012. Sua principal característica é a flexibilidade de horários, já que oferece aulas de manhã, à tarde e à noite, em seis turnos diferentes, cada qual com duração de duas horas e quinze minutos. Com relação à organização pedagógica, as unidades educacionais possuem a possibilidade de escolher a melhor maneira de atender à demanda local, e algumas delas adotam as rodadas temáticas por área de conhecimento, por meio das quais cada turma permanece por vinte e sete dias letivos com as disciplinas que compõem a área. Nesse caso, a ideia de temas geradores defendida por Freire (1985), que rompe com a lógica da educação bancária discutida pelo autor, fomenta ações que levam a comunidade escolar a definir conjuntamente o que será estudado. Para Di Pierro (2017), o atendimento desenvolvido no CIEJA se configura como forma de atendimento adequada ao público demandante:

[...] escolas organizadas exclusivamente para atender jovens e adultos reúnem melhores condições para flexibilizar os tempos e espaços de ensino e aprendizagem com vistas a torná-las mais atrativas e adequadas ao público a que se destinam. A possibilidade de matrícula a qualquer momento do ano, a oferta de jornadas escolares relativamente curtas e múltiplos horários de estudo, a existência de assistência estudantil, o recrutamento seletivo, o trabalho coletivo e a dedicação intensiva dos docentes parecem favorecer esse resultado (DI PIERRO, 2017, p. 104).

Pensar no estudante jovem e adulto, que carrega consigo o peso da bagagem da exclusão, nos faz refletir sobre a importância de uma escola libertadora e de uma educação emancipatória, como defendia Freire (2007). Justamente por flexibilizar tempos, espaços e 
repensar a maneira de construção do conhecimento, é que o projeto CIEJA representa, desde a sua criação, em meados dos anos 2000, um foco de resistência que garante direitos a uma imensa parcela da população excluída do sistema educacional, composta por jovens, adultos, idosos e, também, por pessoas com deficiência.

Em relação ao público da Educação Especial na EJA, apenas nos anos 2000 é que os direitos à educação dessa população começaram a ser citados em documentos nacionais e internacionais, estabelecendo relações entre as duas modalidades de educação. $O$ Documento Nacional Preparatório à VI Conferência Internacional de Educação de Jovens e Adultos - CONFINTEA (BRASIL, 2009, p. 46) reafirma

"o direito ao acesso e à permanência de educandos com necessidades educativas especiais com estrutura material, recursos didáticos, profissionais habilitados e segurança, para adequado atendimento às suas especificidades".

Refletir sobre o universo do estudante jovem e adulto com deficiência, transtornos globais do desenvolvimento (TGD) ou altas habilidades/superdotação (AH/SD) nos leva a pensar acerca da exclusão de maneira potencializada. Glat e Antunes (2012) afirmam que o sujeito da educação, numa visão contemporânea, deve ser dotado de pensamento e linguagem inteligíveis. Os alunos com algum tipo de deficiência, TGD ou AH/SD são excluídos da escolarização formal por não atenderem a esses critérios, o que os leva, muitas vezes, à interrupção da sua trajetória escolar, interrupção resultante do preconceito gerado a partir de uma visão homogênea de sociedade.

De acordo com Siems (2011), a chegada desses alunos tem ocorrido de maneira mais acentuada nos últimos anos, em consequência da ampliação do acesso desses estudantes ao ensino regular. Haas (2015, p. 348) aponta que "esse espaço escolar pode constituir-se como lugar potente e legítimo" de atendimento a esse público, proporcionando desenvolvimento humano e social às pessoas com deficiência, TGD ou AH/SD.

A Lei Brasileira de Inclusão da Pessoa com Deficiência, em seu artigo 28, incumbe ao poder público assegurar um sistema educacional inclusivo em todos os níveis e modalidades, bem como a aprendizagem ao longo de toda a vida. Com base nisso, o CIEJA recebe grande parte das matrículas de jovens e adultos com deficiência, TGD ou AH/SD que não concluíram seus estudos. Em função da ampla oferta de horário e do tempo reduzido de permanência na escola, do atendimento educacional especializado e do transporte escolar gratuito para esse público, a presença desses estudantes tem aumentado consideravelmente.

Segundo Faria (2014), já no ano de 2013, a concentração de estudantes público-alvo da Educação Especial nos CIEJAs era superior à das outras unidades da rede que atendem a essa modalidade de ensino. Atualmente, dados do Centro de Informação Educacional da 
Secretaria Municipal de Educação (SME) apontam que, dos 2068 (dois mil e sessenta e oito) estudantes com deficiência matriculados na EJA em 2016, mais da metade (1170 - mil cento e setenta - ou 56,5\%) frequentavam alguma das 16 (dezesseis) unidades do CIEJA.

A chegada desses estudantes em grande número indica a necessidade de professores da sala regular repensarem a sua prática. Surge, então, o primeiro questionamento deste estudo: como os docentes da sala de aula regular constroem sua prática, seu trabalho docente junto a esses alunos no CIEJA?

Freire (2018) acredita que ensinar exige reflexão crítica sobre a prática, que leva à capacidade de analisar a realidade social, histórica e cultural e criar possibilidades para transformá-la, conduzindo alunos e professores a uma maior autonomia e emancipação. Ampliando essa discussão, Franco (2015, p. 603) acrescenta que "a prática não muda por decretos ou por imposições. A prática pode mudar quando houver envolvimento crítico e reflexivo dos sujeitos da prática". Com relação à prática pedagógica, a autora diz, ainda, que

[...] as práticas pedagógicas se configuram na mediação com o outro, ou com os outros, e é esse outro que oferece às práticas seu espaço de possibilidade. Portanto, as práticas podem funcionar como espaço de resistência e, também, de reverberação de múltiplas dominações [...].

O panorama atual da escola brasileira, orientada pelos pressupostos da educação inclusiva, e o crescimento gradual do número de matrículas de estudantes com deficiência na EJA nos levam a refletir sobre qual a concepção dos professores do CIEJA quanto ao processo de inclusão. Assim, esta pesquisa tem por objetivo analisar as narrativas dos professores sobre sua prática pedagógica, percepções e reflexões sobre a atuação junto a estudantes jovens e adultos com deficiência.

\section{Breves considerações sobre Pedagogia do Oprimido e o estudante jovem e adulto com deficiência}

Com relação ao binômio "oprimido/opressor", fazem-se necessárias algumas considerações. Para Oliveira (2016), oprimidos e opressores são polos opostos das relações sociais de antagonismo; são classes sociais antagônicas e em luta. É fundamental, para os objetivos deste estudo, construirmos uma analogia entre oprimidos e pessoas com deficiência, pensando que, atualmente, oprimidos são todos aqueles excluídos socialmente, e não apenas os excluídos a partir da relação antagônica entre empregadores e trabalhadores. Vale ressaltar, ainda, que, apesar de as ideias de Paulo Freire antecederem 
os movimentos mundiais de inclusão, a essência de seu pensamento mostra-se bastante atual, pois considera as singularidades do sujeito. $O$ grande educador brasileiro explica que

o opressor só se solidariza com os oprimidos quando o seu gesto deixa de ser um gesto piegas e sentimental, de caráter individual, e passa a ser um ato de amor àqueles; quando, para ele, os oprimidos deixam de ser uma designação abstrata e passam a ser homens concretos, injustiçados e roubados (FREIRE, 2018, p. 50).

Assim, a presença de estudantes adultos com deficiência na sala de aula regular os eleva à condição de "homens concretos", nesse caso, injustiçados e roubados por um sistema escolar que reflete a figura do opressor. Portanto, ao serem incluídos no processo de escolarização com equidade, é possível identificar o ato de amor ao qual se referiu Freire.

Os outros conceitos relevantes para a construção desta pesquisa são as concepções de educação bancária, educação problematizadora e dialogicidade, quando nos propomos a analisar a atuação docente junto ao público da Educação Especial.

No tocante à educação bancária, ao discutir as relações educador-educando, Freire apresenta o educador como o narrador/dissertador de uma realidade parada, estática, compartimentada e bem-comportada, alheio à experiência existencial dos educandos, meros ouvintes dessa narrativa:

A narração, de que o educador é o sujeito, conduz os educandos à memorização mecânica do conteúdo narrado. Mais ainda, a narração se transforma em "vasilhas", em recipientes a serem "enchidos" pelo educador. Quanto mais vá "enchendo" os recipientes com seus "depósitos", tanto melhor educador será. Quanto mais se deixem docilmente "encher", tanto melhor educandos serão (FREIRE, 2018, p. 79-80).

Para Freire (2018, p. 95), ao contrário desta, a educação problematizadora, que liberta, rompe com os esquemas verticais característicos da educação bancária, contrapondo-se a ela:

\footnotetext{
O antagonismo entre as duas concepções, uma, a "bancária", que serve à dominação; outra, a problematizadora, que serve à libertação, toma corpo exatamente aí. Enquanto a primeira, necessariamente, mantém a contradição educador-educandos, a segunda realiza a superação.

Para manter a contradição, a concepção bancária nega a dialogicidade como essência da educação e se faz antidialógica; para realizar a superação, a educação problematizadora - situação gnosiológica - afirma a dialogicidade e se faz dialógica.
}

Finalmente, ao propor a dialogicidade na educação, Freire (2018) apresenta considerações importantes sobre o diálogo, que, como fenômeno humano, nos leva à palavra, que, por sua vez, apresenta duas dimensões também importantes para este estudo: ação e reflexão, que, unidas, levam à práxis: 
Mas, se dizer a palavra verdadeira, que é trabalho, que é práxis, é transformar o mundo, dizer a palavra não é privilégio de alguns homens, mas direito de todos os homens. Precisamente por isso, ninguém pode dizer a palavra verdadeira sozinho, ou dizê-la para os outros, num ato de prescrição, com o qual rouba a palavra dos demais. O diálogo é este encontro de homens, mediatizados pelo mundo, para pronunciá-lo, não se esgotando, portanto, na relação eu-tu (FREIRE, 2018, p. 109).

Os professores da EJA "depositam" seus saberes ou constroem, juntos, uma prática educativa baseada nas possibilidades e nas potencialidades de cada estudante, dialogicamente aprendendo ao mesmo tempo em que ensinam?

\section{Método}

Esta é uma pesquisa exploratória, do tipo estudo de caso ${ }^{1}$, que foi realizada no Centro Integrado de Educação de Jovens e Adultos Perus I, região noroeste do município de São Paulo. Para esta pesquisa, optamos por utilizar a identidade de gênero, e não o sexo biológico, solicitando aos professores que se identificassem. Assim, dentre os 14 (quatorze) participantes, 11 (onze) identificam-se como mulheres, 2 (dois) como homens, 1 (um) preferiu não responder, e nenhum participante declarou-se transgênero. Os critérios para seleção foram: 1) possuir estudantes com deficiência matriculados em suas turmas no ano letivo de 2018; e 2) ter interesse em participar da pesquisa.

Os dados foram coletados por meio de um questionário composto por duas partes. A primeira continha dez questões fechadas e uma aberta e foi denominada "Perfil da formação docente". A segunda parte do questionário destinou-se ao relato sobre a prática docente junto ao estudante com deficiência. Neste artigo, apresentaremos apenas os resultados da segunda parte do questionário.

Com relação à análise dos dados, optamos por utilizar o processo de ciclos de codificação, proposto por Saldaña (2016), aplicados ao software ATLAS.ti. Para o autor, a codificação é um processo transitório entre a produção e a análise extensiva dos dados e deve ocorrer de forma cíclica, sendo esse um dos caminhos para a análise qualitativa dos dados. O processo tem início com o procedimento de pré-codificação, anotações preliminares, memo analítica, até chegarmos à criação do código propriamente dito, que, em pesquisa qualitativa, frequentemente, é uma palavra ou frase curta. Esta, simbolicamente,

\footnotetext{
${ }^{1}$ As reflexões e a pesquisa apresentadas neste artigo consistem em um recorte da dissertação de mestrado da autora, intitulada "Educação Especial na EJA: análise do processo de construção da prática docente" defendida em 2020 na Universidade Federal de São Carlos sob a orientação da professora Juliane Aparecida de Paula Perez Campos.
} 
salienta, captura a essência, ou evoca um atributo de uma fração dos dados (SALDAÑA, 2016).

O autor diz, ainda, que a codificação pode ocorrer de maneira manual ou com Computer Assisted Qualitative Data Analysis (CAQDAS), deixando claro que as funções desses softwares consistem em organizar, gerenciar e reconfigurar os dados para uma análise reflexiva, e não em criar os códigos para o pesquisador.

Assim, após a primeira leitura e anotações preliminares, os participantes foram nomeados de P1 a P14 e divididos em dois grupos, a partir das informações sobre formação inicial e continuada em Educação Especial contidas na primeira parte do questionário. $\mathrm{O}$ grupo 1 foi formado pelos professores que tiveram algum tipo de formação, inicial ou continuada, em Educação Especial. O grupo 2, por sua vez, foi formado pelos professores que não tiveram nenhum tipo de formação inicial ou continuada em Educação Especial; tiveram apenas as formações em serviço ofertadas pela escola, como demonstrado no quadro 1.

Quadro 1 - Grupos de acordo com a formação

\begin{tabular}{|l|l|l|l|c|c|c|c|c|}
\hline GRUP0 1 & P1 & P2 & P3 & P5 & P6 & P11 & P13 & P14 \\
\hline GRUPO 2 & P4 & P7 & P8 & P10 & P12 & & & \\
\hline
\end{tabular}

Fonte: Dados da dissertação de mestrado da autora.

A análise inicial dos relatos dos professores nos levou à criação de três códigos: 1 . Flexibilização do currículo; 2. Dialogicidade; 3. Colaboração/interação. Ressaltamos que a criação dos códigos é subjetiva, e estes foram pensados em função da incidência do tema nas respostas dos professores, além de buscar uma relação direta com o referencial teórico.

\section{Resultados e discussões}

Como dito anteriormente, a discussão dos resultados refere-se apenas à análise da prática docente; os dados do "Perfil dos participantes" serão apresentados em outra publicação.

\section{Flexibilização do currículo}

O código Flexibilização do currículo foi criado com base na relação direta entre a ideia de professor reflexivo, proposta por Paulo Freire (2018), e a busca de alternativas para um melhor atendimento das necessidades dos estudantes que são público-alvo da Educação Especial. O quadro 2 ilustra trechos das narrativas dos professores referentes a esse tema. 


\begin{tabular}{|c|c|}
\hline PROFESSOR & NARRATIVA \\
\hline P1 & $\begin{array}{l}\text { As avaliações diagnósticas me levaram a acreditar que a adaptação dos } \\
\text { conteúdos planejados para a turma poderia ser eficaz ao fazer uso de materiais } \\
\text { concretos, pois compreender aquilo que é palpável e se pode vivenciar é mais } \\
\text { imediato e significativo do que trabalhar apenas no campo do simbólico. Para } \\
\text { tanto, caminha junto ao ato de planejar a ação de avaliar: avaliações } \\
\text { diagnósticas e avaliações processuais são intrínsecas ao ato de planejar, e a } \\
\text { mudança de estratégias e abordagens, quando as avaliações mostram que as } \\
\text { adotadas até o momento não estão sendo eficientes, pois, de nada adianta } \\
\text { avaliação, se a mesma não desencadear reflexão. }\end{array}$ \\
\hline P2 & $\begin{array}{l}\text { Na seleção dos conteúdos a serem trabalhados com os estudantes do CIEJA } \\
\text { PERUS I, observou- se, primeiramente, a adequação dos mesmos às } \\
\text { possibilidades sociocognitivas, compreendendo o momento da aula como um } \\
\text { lugar, como um momento para aprendizados, facilitando as correspondências } \\
\text { para melhor compreensão deste processo. }\end{array}$ \\
\hline P5 & $\begin{array}{l}\text { Elaborava desenhos ilustrativos com a temática abordada para a tentativa de } \\
\text { melhor compreensão do assunto. Vídeos pequenos e chamativos foram usados, } \\
\text { algumas vezes, quando a temática era mais complexa. }\end{array}$ \\
\hline P6 & $\begin{array}{l}\text { O estudante participa das aulas, porém não produz texto escrito. Desse modo, } \\
\text { trabalhei com imagens e histórias em quadrinhos para observar como o } \\
\text { estudante compreendia os conteúdos abordados. Em todas as aulas, tínhamos } \\
\text { momentos de exposição oral em que o estudante participava ativamente. } \\
\text { Trabalhamos com o desenho livre e criamos outros métodos de abordagem da } \\
\text { temática saúde. }\end{array}$ \\
\hline P11 & $\begin{array}{l}\text { Em cada temática tratada, foram utilizados recursos visuais, concretos, } \\
\text { dicionário de libras, vídeos e tradução por meio de pesquisa na internet ou } \\
\text { aplicativo no celular. Na rotina educacional, os desafios foram muitos a respeito } \\
\text { de adaptar os conteúdos para os estudantes surdos. Para o trabalho docente, } \\
\text { realizar as adaptações é um avanço para a prática, pois muitos contemplaram } \\
\text { todos os alunos da turma, e não somente os surdos. }\end{array}$ \\
\hline P13 & $\begin{array}{l}\text { Para garantir a aprendizagem, me utilizo da expressão corporal, de recursos } \\
\text { visuais, música, literatura, materiais manipuláveis, a lousa etc. Vale destacar } \\
\text { que a interação, no processo, é medida pelo afeto, respeito e diálogo. }\end{array}$ \\
\hline P14 & $\begin{array}{l}\text { Meu planejamento baseava-se em alternar atividades fáceis para melhorar a } \\
\text { autoestima, e algumas eram iguais às da turma regular, numa tentativa de } \\
\text { incluir ajudando-o a realizar com direcionamento. Muitas vezes, a aula era mais } \\
\text { direcionada para o diálogo, pois o aluno em questão gostava muito de contar } \\
\text { coisas de seu cotidiano, seja com a família, com os professores, seja quanto às } \\
\text { suas jogatinas em videogames e filmes assistidos. }\end{array}$ \\
\hline
\end{tabular}

Fonte: Dados da dissertação de mestrado da autora.

Os professores utilizaram grande variedade de recursos, demonstrando conhecimento sobre o conteúdo abordado e sobre as possibilidades dos estudantes. P1 utilizou o termo "avaliação diagnóstica", o que nos remete à ideia de programação proposta por Freire (1997), não apenas da atividade propriamente dita, mas também de um conhecer mais profundo sobre esse aluno. Isso o levou à utilização de materiais mais concretos, com a expectativa de dar sentido à aprendizagem. No entanto, seu planejamento é constantemente revisto, ocasionando mudanças de estratégias e abordagens em decorrência das respostas vindas do processo de avaliação permanente. Em sua resposta, P1 demonstra ter a consciência crítica defendida por Freire.

Tanto P2 quanto P13 trouxeram, em seus comentários, questões afetivas que indicam seu entendimento sobre o processo de ensino e aprendizagem na escola, que ultrapassa a 
aprendizagem de um conteúdo. A sala de aula é vista como um lugar de aprendizagens, de correspondências, de afeto, de respeito e de diálogo. É a leitura da palavra, mas também a leitura do mundo, como propõe Freire (1997).

Adentrando um pouco mais tecnicamente na questão da leitura de palavras, os professores P5 e P6, entendendo que seus estudantes não dominavam a leitura e a escrita, utilizaram-se da oralidade, de imagens, de desenhos, de histórias em quadrinhos e de vídeos relacionados ao tema da aula. A participação efetiva desses estudantes não estava condicionada a esse saber específico, e a construção do conhecimento ocorreu por outras vias. Esse olhar dos professores vai ao encontro das palavras de Freire (2018, p. 119), quando diz que

Será a partir da situação presente, existencial, concreta, refletindo o conjunto de aspirações do povo, que poderemos organizar o conteúdo programático da educação [...], sendo, neste caso, povo entendido como os estudantes com deficiência e suas especificidades.

P11 foi desafiado a repensar sua prática em função das barreiras linguísticas que a comunicação com o estudante surdo lhe impunha. Freire (1986, p. 93) estabelece importante relação entre comunicação/linguagem e classe social:

[...] Não há como pensar em linguagem sem pensar em ideologia, e, portanto, não é possível tratar o problema da alfabetização sem levar em consideração o corte da classe social.

O problema da linguagem é que a sintaxe, que é exatamente o que joga com a questão da estrutura do pensamento, não é a mesma nas diferentes classes sociais. Se estabelece como certa, obviamente, a sintaxe da classe dominante, e determina-se, no mundo científico, que a linguagem popular não tem gramática.

Temos o professor ouvinte, que representa a classe dominante, portanto, o opressor, e o estudante surdo, com sua "linguagem sem gramática", na figura de oprimido. No entanto, ao fazer buscas na internet, utilizar recursos visuais, dicionário de libras ou aplicativo no celular, pensar e repensar maneiras de atender a esse estudante, P11 humaniza o processo de aprendizagem, marcado, nesse caso, pela violência da opressão linguística. O professor se dá conta de que refletir sobre sua prática e adaptá-la ao estudante com deficiência trouxe benefícios para toda a turma; isso é considerado, por ele, um "avanço para a prática".

P14 aponta, como estratégias principais, a oralidade e o diálogo, utilizando fatos da vida pessoal do estudante no processo de ensino-aprendizagem. Preocupado com o sentimento de exclusão que o educando pode ter por não conseguir realizar as atividades como os outros, P14 não só auxilia diretamente o estudante a fazê-las, como também o incentiva a utilizar seu principal recurso (no caso, a oralidade) no desenvolvimento dessas 
atividades. Ao considerar, como conteúdo, coisas do cotidiano do educando, filmes a que ele assiste e jogos de videogame, o professor aproxima sua prática do pensamento de Freire (1986, p. 92), no tocante à escolha do conteúdo programático:

\begin{abstract}
Na verdade, há um grande problema, de natureza política: quem escolhe os conteúdos da prática educativa? Qual o papel dos educandos, das famílias e da comunidade no processo de escolha e seleção dos conteúdos? Ou seja, esses conteúdos têm relação com uma certa dimensão universal e estarão em função de certas necessidades que precisam ser nacionalmente conhecidas, mas têm a ver com uma grande diversidade cultural nos conteúdos.
\end{abstract}

De maneira geral, os professores do grupo 1 demonstraram, em suas respostas, que programam e avaliam, de forma permanente, suas práticas, refletindo constantemente sobre seu fazer docente a partir das necessidades dos estudantes. Percebemos que há embasamento e segurança em seus comentários, possivelmente, provenientes de sua formação permanente.

O quadro 3 apresenta trechos das narrativas dos professores do grupo 2 concernentes à flexibilização do currículo.

Quadro 3 - Código Flexibilização do currículo - grupo 2

\begin{tabular}{|c|c|}
\hline PROFESSOR & NARRATIVA \\
\hline P4 & $\begin{array}{l}\text { Nos momentos de escrita, realizo algumas propostas individualizadas, de acordo com o nível } \\
\text { de alfabetização de cada um. No planejamento, tento equilibrar a comunicação oral e escrita, } \\
\text { provocando situações que estimulem a realização de algumas atividades que exigem o } \\
\text { raciocínio ou a criatividade dos alunos. A partir, por exemplo, da leitura de um livro, tento } \\
\text { relacionar alguns pontos à realidade do país ou da vida cotidiana de meus próprios } \\
\text { educandos, sempre com a intenção de ouvir tanto os estudantes "normais" quanto aqueles } \\
\text { com algum tipo de deficiência. }\end{array}$ \\
\hline P7 & $\begin{array}{l}\text { No caso da deficiente visual, baixa visão, o conteúdo dado para os outros alunos é o mesmo, } \\
\text { mas amplificando para que a leitura seja facilitada. Muitas vezes, se faz necessário fazer } \\
\text { ditados para que o entendimento seja estabelecido. Alunos com deficiência intelectual e } \\
\text { transtornos globais de desenvolvimento não alfabetizados são recebidos na sala de aula com } \\
\text { jogos, palavras cruzadas, letras móveis, caça-palavras, sempre respeitando o tema que os } \\
\text { outros estudantes estão trabalhando. }\end{array}$ \\
\hline P8 & $\begin{array}{l}\text { Trabalhamos muito com imagens e mapas. Em relação a atividades diferenciadas, } \\
\text { trabalhamos muito com leitura de imagens e confecção de bandeiras para a composição da } \\
\text { sala ambiente de Geografia. }\end{array}$ \\
\hline P9 & $\begin{array}{l}\text { O aluno atendido estava em nível de alfabetização; dentro dessas características, era } \\
\text { necessário adequar as atividades específicas da área/disciplina de forma que se tornasse } \\
\text { funcional. }\end{array}$ \\
\hline P12 & $\begin{array}{l}\text { O planejamento era de acordo com o que ele tinha a necessidade em trabalhar: tinha dia que } \\
\text { ele trazia alguma atividade de alfabetização que a professora dele tinha trabalhado em sala } \\
\text { de aula, que era de português ou matemática. Tinha dia que a gente trabalhava com livro da } \\
\text { sala de leitura (de ensino infantil); a gente lia e, depois, ele digitava no Word. Tinha dia que } \\
\text { ele queria digitar uma carta para alguma professora que ele queria. Nós também chegamos } \\
\text { a encaminhar uma carta digitada para os familiares dele em Minas Gerais. }\end{array}$ \\
\hline
\end{tabular}

Fonte: Dados da dissertação de mestrado da autora. 
Na narrativa de P4, identificamos a importância dada ao "falar com ele", proposto por Freire (2018). Essa relevância é perceptível quando o docente diz tentar relacionar alguns pontos à realidade do país ou da vida cotidiana dos alunos, sempre com a intenção de ouvir tanto os estudantes "normais" quanto aqueles com algum tipo de deficiência. Para o autor,

\begin{abstract}
do momento em que falamos ao educando ao momento em que falamos com ele, ou da necessidade de falar ao educando à necessidade de falar com ele, ou, ainda, é importante vivermos a experiência equilibrada, harmoniosa, entre falar ao educando e falar com ele. Quer dizer, há momentos em que a professora, enquanto autoridade, fala ao educando, diz o que deve ser feito, estabelece limites sem os quais a própria liberdade do educando se perde na licenciosidade, mas estes momentos, de acordo com a opção política da educadora, se alternam com outros em que a educadora fala com o educando (FREIRE, 1997, p. 58).
\end{abstract}

Ao mesclar atividades com ênfase na escrita e na oralidade ou no raciocínio lógico e na criatividade, P4 valoriza diferentes possibilidades de construção do saber.

Os participantes P7, P8 e P9, possivelmente, por serem professores do ensino fundamental II, e não alfabetizadores, demonstraram certa dificuldade em desenvolver seus conteúdos específicos com a ausência da leitura e da escrita por parte desses estudantes, 0 que não os impediu de buscar outras possibilidades de participação. P7 procurou trabalhar o conteúdo proposto por meio de jogos, palavras cruzadas ou letras móveis. Já P8 enfatizou a leitura de imagens e mapas, enquanto P9 foi diretivo ao buscar funcionalidade, ou seja, qualquer recurso que o estudante compreendesse. Os três professores demonstraram programar sua prática e avaliá-la permanentemente, já que não ignoraram as limitações dos estudantes, o que vai ao encontro dos postulados de Freire (1997).

A experiência relatada por P12 difere das demais, porque sua prática docente ocorria durante as orientações de estudos na sala de informática. Todos os estudantes do CIEJA devem frequentar, além das aulas regulares, aulas extras de informática para cumprimento total da carga horária prevista em lei, devendo ser em horário livre e com a orientação de alguns professores. Nesse caso, P12 encontrava-se, semanalmente, com o estudante, que demonstrava muito interesse pelo computador, e esses encontros consistiam em um importante momento de aprendizagem. Justamente por ser em um projeto extraclasse, P12 realizava a mediação da construção dos saberes a partir dos interesses do estudante, o que exige outro tipo de planejar. Trabalhar com um livro da sala de leitura, retomar uma lição de português ou matemática, ou, ainda, escrever e enviar uma carta digitada para familiares distantes são formas de trabalhar com temáticas significativas, ideia defendida por Freire (2018, p. 139). Para ele, 
Nosso papel não é falar ao povo sobre a nossa visão do mundo, ou tentar impô-la a ele, mas dialogar com ele sobre a sua e a nossa. Temos de estar convencidos de que a sua visão de mundo, que se manifesta nas várias formas de sua ação, reflete a sua situação no mundo, em que se constitui. A ação educativa e política não pode prescindir do conhecimento crítico dessa situação, sob pena de se fazer "bancária" ou de pregar no deserto (FREIRE, 2018, p. 120).

Dessa maneira, que sentido teria o trabalho de algum conteúdo programático fechado, como aprender sobre o sistema operacional Windows, por exemplo, em vez dos conteúdos do cotidiano do estudante, relevantes para ele?

Para o educador-educando, dialógico, problematizador, o conteúdo programático da educação não é uma doação ou uma imposição - um conjunto de informes a ser depositado nos educandos - mas a devolução organizada, sistematizada e acrescentada ao povo daqueles elementos que este lhe entregou de forma desestruturada (FREIRE, 2018, p. 116).

Os professores do grupo 2, assim como os do grupo 1, demonstraram programar e avaliar permanentemente a sua prática. No entanto, percebemos que aqueles que não tiveram nenhum tipo de formação em Educação Especial apresentaram mais dificuldades com a questão da não alfabetização, por exemplo.

As narrativas sobre prática docente relativas à flexibilização do currículo apresentadas pelos professores dos dois grupos nos mostraram que, apesar de estratégias diversas no ato de planejar, todos têm, em comum, uma postura político-pedagógica séria e competente, em que são sujeitos de sua prática, responsáveis por criá-la e recriá-la, como proposto por Freire (2005).

Outro aspecto evidente nas narrativas é o compromisso profissional com a sociedade, também defendido pelo autor:

De fato, ao nos aproximarmos da natureza do ser que é capaz de se comprometer, estaremos nos aproximando da essência do ato comprometido.

A primeira condição para que um ser possa assumir um ato comprometido está em ser capaz de agir e refletir (FREIRE, 1979, p. 7).

Portanto, flexibilizar a práxis buscando atender às necessidades educacionais de estudantes público-alvo da Educação Especial é agir e refletir, ou seja, um ato comprometido.

\section{Dialogicidade}

O diálogo é parte fundamental de uma educação problematizadora, defendida pelo referencial teórico adotado neste estudo, e, por isso, ao ser identificado nas narrativas dos participantes, tornou-se um código no processo de análise.

Freire (1967, p. 107) discorre sobre o tema: 
E o que é o diálogo? É uma relação horizontal de A com B. Nasce de uma matriz crítica e gera criticidade. Nutre-se do amor, da esperança, da fé, da confiança. Por isso, só o diálogo comunica. E, quando os dois polos do diálogo se ligam assim, com amor, com esperança, com fé um no outro, se fazem críticos na busca de algo. Instala-se, então, uma relação de simpatia entre ambos. Só aí há comunicação.

A dialogicidade, portanto, é a via de mão dupla que constrói a prática docente, em que as vozes dos estudantes público-alvo da Educação Especial podem ser ouvidas. Vozes ouvidas não apenas pela ação mecânica da fala, mas também pela troca de olhares, pela convivência diária em sala de aula.

O quadro 4 traz as narrativas dos professores do grupo 1 sobre o código Dialogicidade.

Quadro 4 - Código Dialogicidade do grupo 1

\begin{tabular}{|c|c|}
\hline PROFESSOR & NARRATIVA \\
\hline P2 & $\begin{array}{l}\text { Os trabalhos que são realizados têm como principal objetivo a integração dos } \\
\text { alunos com deficiência junto aos demais alunos. Isso gera, no grupo, a } \\
\text { identificação dos diferenciais, pois é a partir das diferenças que surge o } \\
\text { preconceito e, a partir desse embate, os estudantes conseguem reconhecer a } \\
\text { diversidade e superar a discriminação. Mesmo sendo adultos, esse sentimento } \\
\text { está intrínseco em nossa sociedade. }\end{array}$ \\
\hline P3 & $\begin{array}{l}\text { Os sete estudantes que atendo, assim como os outros colegas, são atendidos } \\
\text { igualmente, sem diferença. As atividades são planejadas para atender a todos, } \\
\text { tendo, no seu desenvolvimento, o atendimento a cada estudante. O aluno com } \\
\text { deficiência faz o que ele consegue, sem cobranças por parte do professor. }\end{array}$ \\
\hline P5 & $\begin{array}{l}\text { É sempre enriquecedor ter o educando com deficiência em sala, ao mesmo } \\
\text { tempo, difícil. A estudante que atendi por mais tempo, me ocupei em tratar, no } \\
\text { coletivo, o convívio social. }\end{array}$ \\
\hline P13 & $\begin{array}{l}\text { A minha atuação docente é pautada num trabalho que constrói o conhecimento, } \\
\text { o processo de ensino-aprendizagem a partir do diálogo, dos saberes dos } \\
\text { educandos para leitura crítica do mundo, para compreender o conhecimento } \\
\text { sociocultural e historicamente construído. O meu esforço foi integrar o educando } \\
\text { nesse processo, mas percebo que me falta um saber especializado, técnico, } \\
\text { para que a aprendizagem se efetive. }\end{array}$ \\
\hline
\end{tabular}

Fonte: Dados da dissertação de mestrado da autora.

Notamos que a narrativa de P2 aborda a questão do preconceito e da discriminação, presentes em nossa sociedade. A maneira pela qual o professor procurou lidar com essa problemática foi por meio da interação, que, obviamente, pressupõe diálogo. Ao afirmar que "[...] é a partir das diferenças que surge o preconceito e, a partir desse embate, os estudantes conseguem reconhecer a diversidade e superar a discriminação", P2 sugere que o "embate", ou seja, o diálogo pode auxiliar na mudança da condição de oprimido ocupada pelo EPAEE (estudante público-alvo da Educação Especial). Assim, a relação horizontal, proposta por Freire (2018), além de presente, ultrapassa os pontos A e B, já que envolve todo um coletivo. 
Utilizando os termos "igualmente" e "sem diferença", P3 afirma que dialoga, individualmente, com todos os estudantes. Planejar aulas pensando em cada estudante da turma, destinando tempo para ouvi-los é condição para o diálogo. Sua resposta apresenta, ainda, a questão da compreensão das possibilidades de aprendizagem do estudante com deficiência e da ausência de cobranças. Ausência de cobrança é sinônimo de tolerância e respeito, bases do conceito de diálogo, defendido por Freire (2018).

O convívio social, tratado no coletivo, é a resposta dada por P5 às dificuldades encontradas em sala de aula. É a utilização direta e consciente do diálogo como instrumento de inclusão. O antagonismo das expressões "enriquecedor e, ao mesmo tempo, difícil" nada mais é do que a reflexão crítica do docente acerca do processo de ensino-aprendizagem, em que o educador e o educando ensinam e aprendem.

$\mathrm{Na}$ fala de P13, encontramos quase toda a essência do pensamento freiriano: o diálogo; a valorização dos saberes dos educandos, construídos historicamente; a busca por uma leitura crítica do mundo; e a posição humilde daquele que tem a consciência das limitações dos seus próprios saberes. P13 demonstrou que sua prática vai ao encontro das ideias de Freire (2018) no tocante à sua visão do homem como um ser inconcluso, à consciência de sua inconclusão e ao seu permanente movimento de busca do ser mais. Talvez, o mais significativo de toda a resposta de P13 seja, justamente, o fato de ele pautar toda a sua atuação docente "num trabalho que constrói o conhecimento, o processo de ensino-aprendizagem a partir do diálogo". Nas palavras de Cruz (2018, p. 95),

O diálogo permite o respeito, a valorização do conhecimento e das experiências que o educando/aprendiz traz. Sua visão de mundo e participação não devem ser desconsideradas, negadas ou entendidas de "forma simplista". O aprendizado crítico do conhecimento, de forma significativa, por meio da relação dialógica, sem dúvida, é um dos eixos fundantes e sustentadores da prática pedagógica dos educadores. $\mathrm{O}$ diálogo estará, assim, presente no discurso e na prática dos educadores.

Identificamos, nas respostas dos professores desse grupo, o cuidado de estabelecer o diálogo como elemento base da construção de suas práticas docentes, o que os coloca na condição ensinantes-aprendentes. Como diz Jaspers, citado por Freire (1967, p. 107), "o diálogo é, portanto, o indispensável caminho".

No quadro 5, encontramos trechos das narrativas de alguns professores do grupo 2 sobre o diálogo.

Quadro 5 - Código Dialogicidade do grupo 2

\begin{tabular}{|l|l|}
\hline PROFESSOR & NARRATIVA \\
\hline
\end{tabular}




\begin{tabular}{|c|l|}
\hline P4 & $\begin{array}{l}\text { Tenho muito a aprender com meus educandos. Na verdade, são eles que me dão as pistas } \\
\text { de suas necessidades, seus gostos, seus repertórios e suas possibilidades de ampliação e } \\
\text { interação com os mesmos. Nos meus planejamentos, tento integrar momentos de trabalho } \\
\text { em pequenos grupos e outros individuais ou coletivos. Todos os dias, inicialmente, converso } \\
\text { sobre a rotina e abro espaço para um diálogo sobre algum tema emergente (no grupo, ou a } \\
\text { partir de uma questão individual, busco problematizar e dialogar com a participação de todo } \\
\text { o grupo). }\end{array}$ \\
\hline P10 & $\begin{array}{l}\text { Todas essas e outras atividades realizadas pelo aluno Luiz deixaram claro seu potencial de } \\
\text { aprendizagem, sobretudo, quando se trata de ações que envolvam comunicação. O Luiz se } \\
\text { desenvolveu muito no que tange às inter-relações e demonstra um enorme prazer em estar } \\
\text { nesse ambiente escolar. }\end{array}$
\end{tabular}

Fonte: Dados da dissertação de mestrado da autora.

Tão intensa quanto a fala de P13, é a de P4, que nos mostra como constrói a relação horizontal de A com B não apenas por meio de palavras, mas também por meio de "pistas das necessidades, gostos, repertórios e possibilidades de ampliação e interação" com os educandos. A conversa diária com os estudantes, como parte do seu planejamento, resulta em uma escuta atenta, que modifica o próprio planejamento em função de temas que emergem desse diálogo. A respeito da escuta, Freire (1996, p. 75) considera que

escutar é, obviamente, algo que vai mais além da possibilidade auditiva de cada um. Escutar, no sentido aqui discutido, significa a disponibilidade permanente, por parte do sujeito que escuta, para a abertura à fala do outro, ao gesto do outro, às diferenças do outro. Isso não quer dizer, evidentemente, que escutar exija, de quem realmente escuta, sua redução ao outro que fala.

Talvez, mais relevante que escutar, seja transformar sua prática em função do que se escuta, já que, para o autor, ensinar exige respeito aos saberes dos educandos (FREIRE, 1996). Logo, podemos afirmar, com base em sua narrativa, que P4 constrói uma prática problematizadora e dialógica com seus estudantes.

Em sua resposta, P10 nomeia o estudante. Esse ato involuntário e a maneira como descreveu as qualidades e o desenvolvimento do estudante apontam para o que Freire (1996, p. 86) chamou de "querer bem aos educandos". Esse querer bem e a percepção do prazer que o estudante sente ao compartilhar o ambiente escolar não impediram o docente de avaliar as reais condições do discente. Para Freire (1996, p. 89),

a afetividade não se acha excluída da cognoscibilidade. O que não posso, obviamente, permitir é que minha afetividade interfira no cumprimento ético de meu dever de professor no exercício de minha autoridade. Não posso condicionar a avaliação do trabalho escolar de um aluno ao maior ou menor bem querer que tenha por ele. 
Assim, P10 foi capaz de identificar as potencialidades do estudante em determinada atividade, acompanhar o seu desenvolvimento acadêmico e, com afetividade, perceber sua alegria em estar na escola.

Em linhas gerais, o código Dialogicidade nos mostrou o quão genuinamente alguns participantes vivenciam o diálogo em suas práticas diárias. Suas narrativas nos levaram a refletir sobre as palavras de Freire (1996, p. 35):

É neste sentido, também, que a dialogicidade verdadeira, em que os sujeitos dialógicos aprendem e crescem na diferença, sobretudo, no respeito a ela, é a forma de estar sendo coerentemente exigida por seres que, inacabados, assumindo-se como tais, se tornam radicalmente éticos.

A ética a que se refere o autor, é percebida no ato de planejar, de pensar e de repensar a própria prática e, acima de tudo, dialogar com os estudantes. Até então, esses foram os aspectos apresentados pelos professores do CIEJA Perus I.

\section{Colaboração/interação}

Evidentemente que não posso negar a singularidade da minha existência, porém isso não significa que a minha existência pessoal tenha um significado absoluto em si mesma, isolada das outras existências. [...] O "eu existo" não precede o "nós existimos", mas constitui-se nele (FREIRE, 1978, p. 25).

O código Colaboração/interação foi criado pensando na prática docente como algo coletivo, que não se faz individualmente. "Ninguém educa ninguém, os homens se educam entre si" (FREIRE, 2018, p. 95), por isso, a colaboração envolve tanto a relação com colegas de trabalho quanto a relação com os próprios estudantes com deficiência, presentes nas respostas dos participantes.

O quadro 6 traz trechos das narrativas dos professores do grupo 1 que envolveram essa temática.

Quadro 6 - Código Colaboração/interação do grupo 1

\begin{tabular}{|c|l|}
\hline PROFESSOR & \multicolumn{1}{|c|}{ NARRATIVA } \\
\hline P3 & $\begin{array}{l}\text { Com o apoio das professoras da SRM,[Sala de Recursos Multifuncionais] } \\
\text { conseguimos ampliar o atendimento à necessidade desses alunos com outras } \\
\text { atividades que envolvem matemática e linguagem. Eles se sentem à vontade } \\
\text { com o grupo, participam, dão opinião, se sentem parte. }\end{array}$ \\
\hline P5 & $\begin{array}{l}\text { Com a ajuda das PAEEs [Professora de Atendimento Educacional } \\
\text { Especializado], elaborava desenhos com a temática abordada, para a tentativa } \\
\text { de melhor compreensão do assunto. Vídeos pequenos e chamativos foram } \\
\text { usados, algumas vezes, quando a temática era mais complexa. }\end{array}$ \\
\hline P11 & $\begin{array}{l}\text { A participação da professora do AEE [Atendimento Educacional Especializado] } \\
\text { foi fundamental no processo de compreensão e conhecimento sobre a surdez. }\end{array}$ \\
\hline
\end{tabular}




\begin{tabular}{|l|l|}
\hline & $\begin{array}{l}\text { Também em parceria com o AEE, todas as quintas, foram dadas aulas de } \\
\text { LIBRAS para a turma, algo que mobilizou o interesse e a vontade de aprender } \\
\text { a língua, além de promover um maior contexto entre os educandos. }\end{array}$ \\
\hline
\end{tabular}

Fonte: Dados da dissertação de mestrado da autora.

As narrativas de P3 e P5 trazem, respectivamente, o "apoio" e a "ajuda" das professoras da Sala de Recursos Multifuncionais no planejamento das atividades. Essas respostas indicam que a interação entre os professores da sala regular e as especialistas em AEE não se estabelecia apenas nos encontros formativos, uma vez que o ensino colaborativo ainda não faz parte das atribuições dos professores de atendimento educacional especializado na rede pública municipal de ensino de São Paulo, apesar de constar na Portaria $n^{\circ} 8764$ de 23 de dezembro de 2016. Existiu uma troca de saberes em outros momentos, além da aula, a qual foi importante para a compreensão do assunto e ampliação do atendimento das necessidades desses estudantes. Assim, nas palavras de Freire (1995, p. 2),

é analisando a minha prática com os outros que analisam, também, a sua prática, que é possível que eu descubra, na prática dos outros, alguma coisa que ilumine problemas que eu tinha, ou tenho, na minha prática. É analisando a prática, discutindo os obstáculos encontrados que eu percebo a teoria na prática. A prática, não é, por exemplo, a sua teoria, mas a prática engendra um certo saber. É preciso que eu me aproprie, com lucidez, da teoria que está sendo vivida na prática que eu estou realizando.

É justamente nessas trocas de saberes entre colegas de profissão, que a prática vira teoria e vice-versa. O resultado dessa interação, de acordo com P3, consiste na participação, na possibilidade de expressar a própria opinião e no sentimento de pertencimento dos estudantes público-alvo da Educação Especial.

A narrativa de P11 vai um pouco além da colaboração/interação apresentada por P3 e P5, porque envolve o aprofundamento de um saber específico por parte do professor da sala regular, no caso, a surdez, e uma ação que modificou o próprio currículo ao incluir aulas de libras semanais para toda a turma. Notamos que houve uma mobilização geral para que o estudante surdo fosse incluído no processo de ensino- aprendizagem, ocorrida graças à parceria entre os professores. "É o encontro dos sujeitos para transformação do mundo em colaboração" (FREIRE, 2018, p. 227). Ainda nas palavras do autor,

A colaboração, como característica da ação dialógica, que não pode dar-se a não ser entre sujeitos, ainda que tenham níveis distintos de função, portanto, de responsabilidade, somente pode realizar-se na comunicação. O diálogo, que é sempre comunicação, funda a colaboração (FREIRE, 2018, p. 228). 
A presença da articulação entre o professor especialista e o da classe comum, discutida em estudos como os de Santos (2016) e Pagnez e Prieto (2016), acaba por supervalorizar algo que deveria ser intrínseco ao cotidiano escolar.

É possível afirmar, a partir das narrativas dos professores do grupo 1 quanto ao código Colaboração/interação, que há, entre eles, o compromisso com a prática docente problematizadora, o que, por isso mesmo, torna perceptível a luta coletiva diária pela inclusão dos estudantes público-alvo da Educação Especial.

O quadro 7 contém as narrativas dos professores do grupo 2 que envolveram o tema.

Quadro 7 - Código Colaboração/interação do grupo 2

\begin{tabular}{|c|l|}
\hline PROFESSOR & \multicolumn{1}{c|}{ NARRATIVA } \\
\hline P4 & $\begin{array}{c}\text { Atividades interativas com outros professores, saídas pedagógicas, leitura em } \\
\text { espaços diferentes, como na sala de leitura, são outros pontos considerados em } \\
\text { meus planejamentos. }\end{array}$ \\
\hline P10 & $\begin{array}{l}\text { Só participam das aulas de apoio as professoras do fundamental I e alguns } \\
\text { alunos do fundamental II, eu e o professor de Arte. Propusemos aos alunos a } \\
\text { confecção de pequenas mandalas para a criação de um móbile que fazia parte } \\
\text { da exposição que homenagearia o artista plástico Arthur Bispo do Rosário. } \\
\text { Outras atividades foram desenvolvidas com o Luiz, com minha participação } \\
\text { direta ou indireta, como foi a entrevista, em que o aluno era o protagonista } \\
\text { entrevistador. }\end{array}$ \\
\hline $\begin{array}{l}\text { Ele sempre pedia ajuda para mexer no celular também. Entrávamos no no no } \\
\text { Facebook para escrever para os parentes dele. Gostava de ver, também, alguns } \\
\text { vídeos, no Youtube, de programas de artistas de que ele gostava muito, pois } \\
\text { estava sem TV em casa e falava que perdia [...]. As vezes, ele pedia para ouvir } \\
\text { algumas músicas, também pelos vídeos do Youtube [...]. }\end{array}$ \\
\hline
\end{tabular}

Fonte: Dados desta pesquisa.

Nesse grupo, percebemos que a colaboração se deu entre os próprios professores da sala regular para P4 e P10, enquanto P12 descreve sua forma de interação com o estudante durante os encontros na sala de informática.

Retomando o ponto central da questão proposta, que era o planejamento da prática, P4 afirma que "atividades interativas com outros professores e saídas pedagógicas" fazem parte do seu pensar docente, ou seja, o professor não concebe sua prática de maneira individualizada, mas, sim, com os outros e em diferentes espaços, como defende Freire (1995).

A prática descrita por P10 envolve a parceria entre professores do ensino fundamental I e II, o que, para Raposo e Maciel (2005), representa um ganho no desenvolvimento pessoal e do projeto político-pedagógico da escola, já que denota que os objetivos comuns se sobressaem aos objetivos individuais dos professores. 
Outra característica comum, apresentada nas narrativas de P4 e P10, é a grande diversificação de atividades em suas práticas, favorecida, possivelmente, pelo trabalho colaborativo desenvolvido por eles.

Diferentemente dos demais, P12 evidenciou, em sua resposta, a interação estabelecida com o educando durante a prática. O professor exerceu o papel de mediador do processo de comunicação do estudante com deficiência e o mundo externo, naquele momento, inacessível a ele fora do ambiente escolar. P12 teve acesso ao universo desse discente, conhecendo seus gostos e sua família. Isso, segundo Freire (1996, p. 6), exige o "querer bem aos educandos e o reconhecimento e a assunção de sua identidade cultural".

\section{Considerações finais}

O acesso à educação básica, por parte de jovens e adultos público da Educação Especial no município de São Paulo, tem aumentado de maneira gradual e considerável, especialmente, a partir do surgimento dos Centros Integrados de Educação de Jovens e Adultos, que concentram, em apenas 16 unidades, 57\% desse público.

A inclusão efetiva desses estudantes no processo de escolarização perpassa não apenas pelo acesso e pela permanência garantidos por lei e reafirmados pelo Atendimento Educacional Especializado ofertado em tal segmento, mas também pela atuação docente junto a esses educandos na sala de aula regular. Para tanto, é necessário levarmos em consideração a pluralidade da EJA e as especificidades desse público, em especial, o que exige diversos saberes do professor.

Considerando a maneira como parte desses saberes foram e são construídos, este estudo teve por objetivo ouvir os professores da sala regular ao se propor a analisar as narrativas sobre prática docente junto a esses estudantes. Os professores demonstraram refletir criticamente sobre suas ações pedagógicas, já que o planejamento das aulas era constantemente revisto e modificado de acordo com as necessidades e potencialidades dos estudantes. Essa flexibilização do currículo apresentada pelos participantes indica o comprometimento ético com a profissão, mas, acima de tudo, com os educandos.

Além da conscientização inerente àqueles que refletem sobre sua prática, identificamos, no grupo de professores, a dialogicidade, presente tanto no ato de planejar quanto no trato com os estudantes. O diálogo, base de uma educação problematizadora, esteve presente em um bom número de narrativas, reforçando a ideia de valorização dos saberes dos educandos na construção de uma prática mais justa e inclusiva.

Outro aspecto relevante foi que, além de flexibilizar o currículo e dialogar, notamos que parte do grupo realiza suas ações em parceria com outros professores, seja da sala de 
recursos multifuncionais, seja da própria sala regular. Isso indica que, para eles, a colaboração também consiste em um importante pilar da prática docente, construída de maneira coletiva, e não individualizada.

Finalizamos este artigo afirmando que não existe escola perfeita e que este estudo reflete apenas uma pequena parte da realidade do CIEJA Perus I. No entanto, é preciso ressaltar a grandeza com que este grupo de pessoas luta, diariamente, por uma sociedade mais justa e inclusiva. Elas possuem a humildade de reconhecer que, obviamente, ninguém sabe tudo; possuem, ademais, a amorosidade, sem a qual o trabalho docente perde o significado. Têm coragem de lutar, ao lado da coragem de amar e, acima de tudo, têm a tolerância que nos ensina a conviver com o diferente, aprender com ele e respeitá-lo.

\section{Referências}

ARROYO, M. G. Passageiros da noite: do trabalho para a EJA: itinerários pelo direito a uma vida justa. Petrópolis: Vozes, 2017.

BEISIEGEL, C. R. A educação de jovens e adultos analfabetos no Brasil. Alfabetização e Cidadania. São Paulo, nº 16, p. 19-27, jul. 2003.

BRASIL. Constituição (1988). Constituição da República Federativa do Brasil: versão atualizada até a Emenda n. 77/2014. Disponível em: http://goo.gl/HwJ1Q. Acesso em: 10 maio 2018.

Lei no 13.146, de 6 de julho de 2015. Institui a Lei Brasileira de Inclusão com Pessoa com Deficiência. Estatuto da Pessoa com Deficiência. Brasília, 2015.

Parecer CEB, $\mathbf{n}^{\circ}$ 2, de 10 de maio de 2000. Dispõe sobre as Diretrizes Curriculares Nacionais para a Educação de Jovens e Adultos. Acesso em: 07 jun. 2018.

Seção 1, p. 66.

. Resolução CNE/CEB 3/2010. Diário Oficial da União, Brasília, 16 de junho de 2010,

Documento Nacional Preparatório à VI Conferência Internacional de Educação de Adultos, VI CONFINTEA. Ministério da Educação. Secretaria de Educação Continuada, Alfabetização e Diversidade e Inclusão, 2016.

CONFERÊNCIA Mundial de Educação para Todos. Declaração Mundial de Educação para Todos. Plano de ação para satisfazer as necessidades básicas de aprendizagem. Brasília: UNICEF, 1990.

CRUZ, T. Dialogando com Paulo Freire: formação continuada de coordenadores (as) pedagógicos (as) na educação de jovens e adultos - EJA. Curitiba: Appris, 2018.

DI PIERRO, M. C. Centros públicos de educação de jovens e adultos no Estado de São Paulo. São Paulo: FE-USP, 2017. 
FARIA, V. E. P. A trajetória do projeto CIEJA entre as políticas públicas de EJA na cidade de São Paulo. 2014. 157 f. Dissertação (Mestrado) - Programa de Pós- graduação em Educação. Faculdade de Educação da Universidade de São Paulo, São Paulo, 2014.

FRANCO, M. A. S. Práticas pedagógicas de ensinar-aprender: por entre resistências e resignações. Educação e Pesquisa, São Paulo, v. 41, n. 3, p. 601-614, jul./set. 2015.

FREIRE, P. R. N. Pedagogia do oprimido. Rio de Janeiro: Paz e Terra, 2018, $17^{a}$ ed.

Educação na cidade. 6. ed. São Paulo: Cortez, 2005.

Pedagogia da indignação: cartas pedagógicas e outros escritos. São Paulo: Editora UNESP, 2000.

1997.

Professora sim, tia não: cartas a quem ousa ensinar. São Paulo: Olho d’Água,

. Pedagogia da autonomia: saberes necessários à prática educativa. São Paulo:

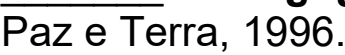

Cartas a Cristina. Rio de Janeiro: Paz e Terra, 1994.

; GUIMARÃES, S. Aprendendo com a própria história. Rio de Janeiro: Paz e Terra, 1987.

A tragédia de ser ou não ser contemporâneo. 1986. Disponível em: http://www.acervo.paulofreire.org:8080/jspui/handle/7891/1129. Acesso em: 10 jan. 2020.

Educação e Mudança. Rio de Janeiro: Paz e Terra, 1979.

Educação como prática da liberdade. Rio de Janeiro: Paz e Terra, 1967. Disponível em https://cpers.com.br/paulo-freire-17-livros-para-baixar-em-pdf/. Acesso em 15 jun. 2019.

GALVÃO, A. M.; DI PIERRO, M. C. A construção social do preconceito contra o analfabeto na história brasileira. Preconceito contra o analfabeto. São Paulo: Cortez, 2013, p. 31-54 (Coleção Preconceitos, vol. 2).

GLAT, R. \& ANTUNES, K. C. V. Pesquisa em Educação Especial: reflexões sobre sujeitos, ética e metodologia. TAQUETTE, S. R.; CALDAS, C. P. (Orgs.). Ética e pesquisa com populações vulneráveis. Rio de Janeiro: Eduerj, p. 267-292, 2012.

HAAS, C. Educação de jovens e adultos e Educação Especial: a (re)invenção da articulação necessária entre as áreas. Educação. Santa Maria, v. 40, n. 2, p. 347-360, maio/ago. 2015.

HADDAD, S.; DI PIERRO, M. C. Escolarização de Jovens e Adultos. Revista Brasileira de Educação, n. 14, p. 108-130, mai./jun./jul./ago. 2000. Disponível em: <http://www.scielo.br/pdf/rbedu/n14/n14a07.pdf>. Acesso em: 05 jul. 2017.

IBGE - Instituto Brasileiro de Geografia e Estatística. Disponível em: http://www.ibge.gov.br. Acesso em: 02 jan. 2020. 
OLIVEIRA, I. A.; SANTOS, T. R. L. Educação Especial de jovens e adultos: um olhar para o atendimento educacional em escolas especializadas. Anped $38^{\circ}$ Reunião Nacional, GT15 Educação Especial - Trabalho 321, São Luís, MA, 2017.

OLIVEIRA, A. R. Dicionário Paulo Freire. Belo Horizonte: Autêntica Editora, 2016.

PAGNEZ, K. S. M. M.; PRIETO, R. G. Atendimento Educacional Especializado em São Paulo. Journal of Research in Special Educational Needs, v. 16, n. 1, p. 201- 206, 2016.

SALDAÑA, Johnny. The coding manual for qualitative researchers. London: Sage, 2016.

SÃO PAULO-SP. Secretaria Municipal de Educação. Diretoria de Orientação Técnica. Educação de Jovens e Adultos. Educação de Jovens e Adultos: princípios e práticas. São Paulo: SME / DOT, 2016.

Portaria nº 8764 de 23 de dezembro de 2016.

SIEMS, M. E. R. Educação de jovens e adultos com deficiência: saberes e caminhos em construção. Educ. foco. Juiz de Fora, v. 16, n. 2, p. 61-79, set. 2011/fev. 2012. Disponível em: http://www.ufjf.br/revistaedufoco/files/2012/08/Texton-031.pdf. Acesso em: 29 ago. 2018.

Recebido em: 10/08/2021

Aceito em: 27/10/2021 